\title{
LEGISLAÇÃO, SUSTENTABILIDADE E MORFOLOGIA URBANA: O CASO DE PASSO FUNDO, RS, BRASIL
}

\author{
Autor: Adriana Gelpi, Rosa Maria Locatelli Kalil, João Henrique Cenci \\ Universidade de Passo Fundo \\ Email: agelpi@upf.br, kalil@upf.br, 141903@upf.br
}

\section{RESUMEN}

A revisão dos Planos Diretores Municipais sob as diretrizes do Estatuto da Cidade tem qualificado a urbanização dos municípios brasileiros. A legislação é reconhecida por tentativas de inovação na produção do território e na democratização dos espaços da cidade. Este trabalho objetiva pesquisar a revisão do Plano Diretor do Município de Passo Fundo/RS e pontuando a nova legislação, identificar aspectos de sustentabilidade incorporados à carta e sua materialização no espaço urbano. Como metodologia analisa, compara e registra transformações na legislação municipal, na cartografia e na paisagem urbana. Conclui abordando que a implementação da legislação sobre o território, contribui para municípios e espaços urbanos mais democráticos e sustentáveis.

Palabras clave: 1; plano diretor 2; estatuto da cidade, 3; morfologia urbana e sustentabilidade

\begin{abstract}
A review of the Master Plans under the guidelines of the City Statute has qualified the urbanization in Brazilian towns. Legislation is recognized by attempts of innovation in the production of the territory and in the democratization of spaces in the city. Therefore, the objetive of this work is to research the review of the Master Plan of Passo Fundo/RS and, featuring the new legislation, identifying aspects of sustainability incorporated into the letter and its materialization. As methodology, it analyzes, compares and records changes in the legislation, cartography and urban landscape. It concludes approaching that the legislation implementation upon the territory contributes to more democratic and sustainable urban spaces and towns.
\end{abstract}

Key-words: 1 ; master plan 2; city statute, 3 ; urbanmorphology and sustainability 


\section{INTRODUÇÃO}

O planejamento municipal através da legislação urbana e dos planos diretores revela-se importante ferraemnta na ordenação e apropriação do território. Os regramentos propostos sob a influência do Estatuto da Cidade (2001) trazem avanços na democratização do planejamento, na sua materialização e na sustentabilidade dos municípios. Como instrumento de planejamento, de legislação e de organização da intervenção urbana, os planos diretores municipais apresentam e viabilizam novos paradigmas de renovação urbana em áreas centrais consolidadas e de expansão regulamentada em áreas periféricas e fragilizadas.

\section{OBJETIVOS}

O trabalho tem como objetivo geral analisar o Plano Diretor de Desenvolvimento Integrado do Município de Passo Fundo - o PDDI, legislação reelaborado em 2006, verificando se esta, realizada através de revisão do Plano Diretor de 1984, e após a promulgação do Estatuto da Cidade (2001) apresenta em seu planejamento, avanços relativos à sustentabilidade municipal. Como objetivos específicos, define e compara indicativos que abordem a justiça social através de zoneamentos de uso do solo e de preservação ambiental, verificando em levantamento de campo, se a legislação proposta está sendo implementada.

\section{METODOLOGIA: SELECIONANDO E COMPARANDO PARÂMETROS DE PLANEJAMENTO E DE SUSTENTABILIDADE}

Para realizar a pesquisa utilizou-se como metodologia, a identificação de parâmetros de sustentalidade para depois comparar sua proposição em ambos os planos, verificando sua implantação no território municipal. Em relação a parâmetros de sustentabilidade urbana, os Indicadores Comuns Europeus para a Sustentabilidade Local (European Communities, 2001) exploram o tema: 1) satisfação dos cidadãos com a comunidade local, 2) contribuição local à mudança no clima global, 3) mobilidade local e transporte, 4) acessibilidade às áreas verdes e serviços 5) qualidade do ar, 6) deslocamento casa - escola para crianças, 7) gestão sustentável de autoridades e empresas, 8) poluição acústica, 9) uso sustentável do território, 10) produtos sustentáveis.

De acordo com Andrade (2005), foram identificados princípios de sustentabilidade associados à morfologia urbana e que vêm sendo observados nas políticas de ordenamento territorial e planejamento urbano das cidades européias, entre eles: 1) equilíbrio entre desenvolvimento urbano e conservação do solo agrícola, florestal, e de áreas verdes para lazer, 2) conservação do solo, dos ecossistemas e dos entornos naturais; 3) mescla de funções urbanas e equilíbrio entre habitação/trabalho; 4) diversidade social nos bairros e nos edifícios; 5) controle dos deslocamentos e do tráfego rodado; 6) proteção do ar e da água; 7) redução de moléstias causadas pelo ruído; 8) gestão dos resíduos; e 9) preservação dos conjuntos urbanos de interesse e do patrimônio imobiliário.

Scussel (2007) coloca que analisando os princípios de sustentabilidade, verifica-se que os padrões urbanísticos sempre estiveram presentes enquanto diretrizes formadoras do espaço das cidades. Jacobs (1967) já abordava que uma forma de sustentar viva e saudável a estrutura urbana é manter sua diversidade. O bairro deve cumprir mais que uma função primária, não podendo especializar-se. A maioria das quadras deve ser curta, com ruas freqüentes, oportunizando a dobra de esquinas. Da mesma forma, o bairro deve mesclar edifícios de idade e condições variadas e ser suficientemente denso, independentemente da hora do dia, sem áreas vazias e desprovidas de ânima urbana.

Entendemos então, como um dos aspectos da cidade sustentável, aquele que bem distribui os serviços e equipamentos, promovendo a diversificação urbana. É neste sentido que o plano diretor deve contribuir, buscando cumprir seu instrumento de orientação da expansão e renovação urbana, na gestão dos investimentos e na diversificação do uso do solo. Nesse trabalho, como indicadores de sustentabilidade urbana, exploramos o planejamento que contemple zoneamento equilibrado entre desenvolvimento urbano e conservação do solo dedicado às atividades agrícolas, florestais e de lazer. A existência de centralidades e subcentralidades urbanas, que democratizam a acessibilidade e racionalizam deslocamentos, os zoneamentos diversificados de uso do solo e os índices urbanísticos que permitam a permeabilidade da água, do ar e do sol no tecido urbano.

3.1) zoneamento de uso do solo - para Deák (2017), o uso do solo corresponde ao conjunto de atividades realizadas pela sociedade sobre a aglomeração urbana assentada em localizações individuais combinadas com padrões ou tipos de assentamento. Para o autor, o "uso do solo é uma combinação de um tipo de uso (atividade) e de um tipo de assentamento (edificação). Del Rio (1990) coloca que o uso do solo trata de tipos de funções e intensidades de utilização do solo nas edificações. $O$ autor afirma que a variedade e a mistura de funções compatíveis entre si e sua utilização nas 24 horas do dia, com densidades compatíveis, pode gerar áreas urbanas com vitalidade, postura diversa daquela preconizada pelo Movimento Moderno, em sua proposição de rigidez de usos, a monofuncionalidade de setores urbanos. 
De acordo com o ITDP (2014), a combinação equilibrada entre usos e atividades complementares como uso residencial e comercial numa mesma edificação, promove espaços urbanos com mais vitalidade, trazendo sensação de segurança, atraindo pedestres e ciclistas, atraindo vida. O uso misto reduz a natureza pendular dos deslocamentos casa-trabalho-casa, diminuindo consumo de energia, moradias de diferentes custos permitem que trabalhadores morem mais perto do trabalho evitando a dependência do transporte e de energia.

Numa revisão dos zoneamentos de usos urbanos, compreendemos que a multifuncionalidade do uso do solo, planejada de forma adequada em uma mistura de usos utilizados 24 horas por dia, tornam a cidade mais sustentável. Isto se dá por utilizar-se a custosa infraestrutura urbana em todas as horas do dia, atraindo pessoas, evitando deslocamentos veiculares, promovendo a segurança e facilitando a mobilidade a pé e em ciclovias. Os multiusos urbanos também promovem a construção de lugares, a vivência dos espaços abertos, dos jogos e diversões ao ar livre.

3.2) Centralidades e subcentralidades urbanas - para Villaça (1998) são os centros e subcentros (existentes e incentivados), na área urbana do município e que fazem parte da estrutura da cidade. Os centros e subcentros são entendidos como zonas de oferta bem distribuídas das facilidades urbanas, definidas pelo zoneamento do uso do solo, que atendem à comunidade nas necessidades básicas de trabalho, educação, comércio, serviços, transporte e lazer, democratizando o acesso aos benefícios urbanos e diminuindo a necessidade de deslocamentos onerosos e de consumo de energia. Cidades mais sustentáveis disponibilizam a seus moradores uma diversidade de centros urbanos, criando lugares e atraindo usos diferenciados, que atendem à população, contribuindo para deslocamentos racionais com a preservação de tempo e energia.

3.3) Os Índices urbanísticos - são parâmetros norteadores e permissíveis da forma da construção e densidade urbana. De acordo com Freitas e Lombardo (2007), estudos sobre planejamento ambiental trazem novos paradigmas para o desenvolvimento sustentável. Ressaltam que usos e ocupação do solo induzem a diferentes condições de conforto ambiental, quando altas temperaturas são verificadas em áreas com crescimento vertical intenso, densidade demográfica excessiva e pouca quantidade de vegetação. Conforme Edwards (2004), o papel que desempenham edifícios e cidades é fundamental na concepção do desenvolvimento sustentável. Permitem, quando propostos adequadamente, a utilização máxima da infraestrutura ofertada, otimizando redes em função da monofuncionalidade sazonal ou por baixa demanda. A ótima utilização dos insumos e redes disponíveis contribui para uma gestão qualificada, para a racionalização de custos e de investimentos municipais, liberando valores a serem investidos em áreas fragilizadas ou na extensão de equipamentos públicos para toda a população.

3.4) O planejamento municipal como estudo de caso - o estudo de caso dá-se em Passo Fundo, município pólo ao norte do Rio Grande do Sul, com 200.000 habitantes. Como importante centro biomédico e estudantil no sul do país desenvolveu-se através da agroindústria e da prestação de serviços, destacando-se como importante entroncamento rodoferroviário entre São Paulo e Buenos Aires (Quadro 1).

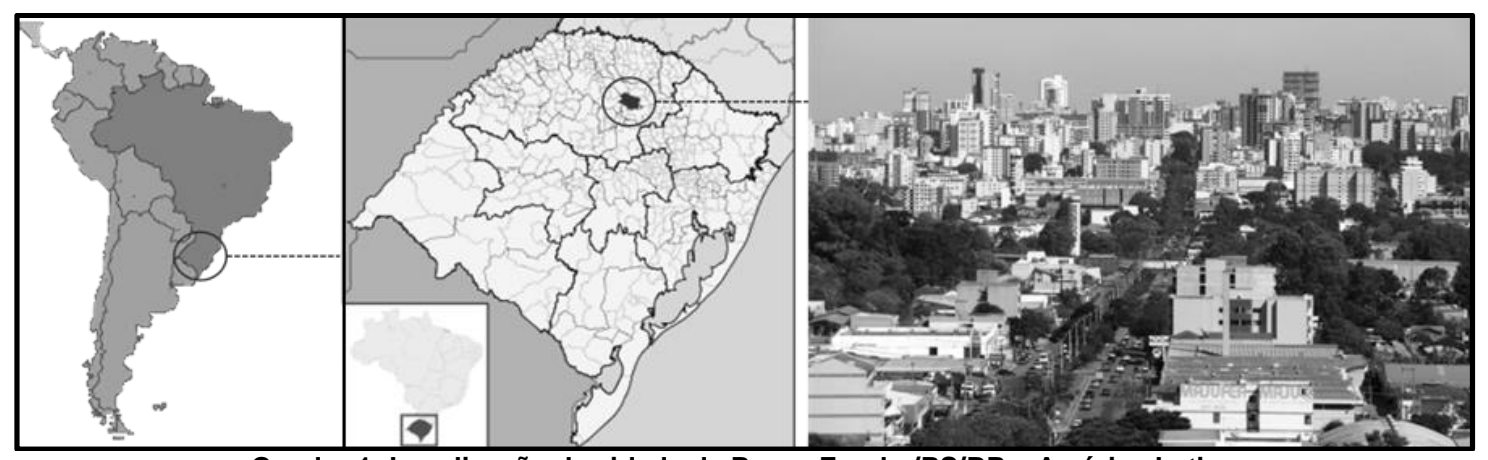

Quadro 1: Localização da cidade de Passo Fundo /RS/BR e América Latina

Fonte: Wikipedia; blogoosfero.cc/ipea

A cidade recebeu seu primeiro plano de diretrizes urbanas em 1919, realizado por Saturnino de Brito focando o saneamento urbano através de infraestrutura sanitária, tratamento e abastecimento de água, além de diretrizes de embelezamento e de expansão urbana (GOSCH, 2002). Em 1953, seu primeiro plano diretor, orientou o crescimento da cidade, localizando equipamentos coletivos no centro urbano que já ocupava 1.400 ha, sendo 80 deles na área central, mais adensada.

Em 1984, foi elaborado o II Plano Diretor de Desenvolvimento Urbano (II PDDU), projeto que além de procurar conter a urbanização entre as vias perimetrais sul e leste, incentivou o adensamento e verticalização da área central, reforçando uma condição já existente no plano de 1953. Essa tendência significou para Tedesco et al. (2007), uma alteração no valor do solo no centro da cidade, estabelecendo altas taxas de ocupação e 
índices de aproveitamento. O impacto deste zoneamento de índices pode ser avaliado através do volume da construção civil realizada no período de 1980-1999, quando foram construídos cerca de três milhões de metros quadrados, aproximadamente 16.000 pavimentos. Nesse período, a cidade ganhou nova escala e 0 edifício de apartamentos consolidou-se como padrão para a vida moderna do passo-fundense. Para Sobarzo (2010, p. 92),

\begin{abstract}
"Essa tendência à concentração da verticalização no centro foi incentivada pelo II Plano Diretor de Desenvolvimento Urbano (II PDDU) de 1984, respondendo a interesses públicos e privados. O interesse do poder público era dar a cidade uma imagem de grande centro urbano. Já os interesses privados centravam-se na possibilidade de estimular a construção e os negócios imobiliários. Assim, o plano significou uma alteração no valor do solo do centro, estabelecendo altas taxas de ocupação e índices de aproveitamento. (...) pode ser exemplificada pela não obrigatoriedade dos recuos entre as construções e a dispensa de vagas de estacionamento para apartamentos tipo quitinete e um dormitório".
\end{abstract}

No início do século XXI, a área urbana de Passo Fundo encontra-se parcialmente contida pelas avenidas perimetrais que a contornam, evitando que o tráfego pesado adentre seu espaço urbano. A cidade está estruturada no sentido leste - oeste pela Avenida Brasil e no sentido norte-sul pelas avenidas Sete de Setembro e Presidente Vargas, sendo o cruzamento destas avenidas, a área central e verticalizada da cidade. No espaço central, localiza-se maior número de equipamentos, as instituições que coordenam e polarizam toda região, as melhores facilidades, as áreas de lazer e recreação. No entorno do centro, acomodam-se bairros e loteamentos, costurados de forma desencontrada, formando um tecido de áreas em adensamento permeadas por áreas vazias. Reproduzindo cidades maiores, a periferia é rarefeita, com loteamentos habitacionais carentes, não havendo equipamentos adequados ou suficientes para educação, esporte, cultura e recreação.

Paralelamente à verticalização da área central, ocorreu o processo de expansão urbana em loteamentos populares. Nos anos de 1980 e 1999 foram aprovados 38 novos loteamentos pela Prefeitura, somando área de 2.401.052 metros quadrados, sendo oferecidos 5.177 lotes para atender a demanda da população originalmente rural. Esta expansão urbana, autorizada pelo poder público, formou periferia desprovida de infraestrutura adequada, sem saneamento básico e integração com o centro urbano consolidado (GOSCH, 2005). Constatou-se que o PDDU de 1984, ao incentivar a concentração e densificação urbana, criou também, nesta renovação edilícia, vários conflitos no centro da cidade. Verificou-se a degradação ambiental e o sombreamento urbano trazido pela verticalização, o aumento dos riscos nas áreas de abastecimento em função do adensamento populacional na área central, a poluição orgânica, e a contaminação do rio Passo Fundo pelo esgoto doméstico e pluvial sem o devido tratamento e proteção ambiental (Quadro 2).

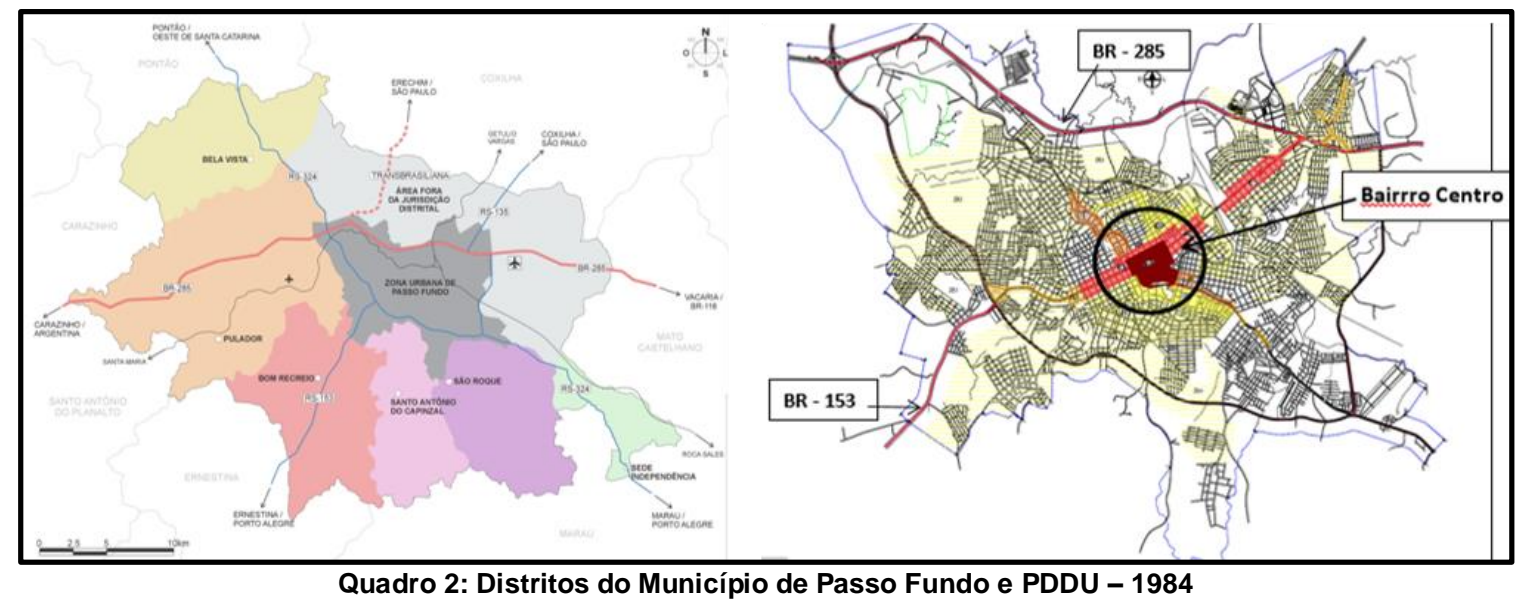

Fonte: PREFEITURA MUNICIPAL DE PASSO FUNDO (2014); GELPI, A. et al. (2012)

\title{
4. ANALISANDO O PLANEJAMENTO E A SUSTENTABILIDADE
}

Para Villaça (1998) "a década de 1990 foi o fim de um período na história do planejamento urbano brasileiro, porque marca o início do processo de politização, fruto do avanço da consciência e organização populares. Esta politização ficou clara nas metodologias de elaboração e dos conteúdos de alguns planos até os debates travados, nos legislativos e fora deles, em várias cidades importantes do país". Mas conforme o autor, no Brasil, os planos diretores têm histórico duvidoso. Quando passaram a ser elaborados no país, a partir dos anos 1960, em sua maioria, não atingiram os objetivos a que se propuseram. Em determinado período, os planos passaram a valer por si sós, e não por seus resultados, funcionando mais como um produto intelectual, descolados da realidade, inserindo-se na produção de um enorme arsenal de idéias sobre a cidade e sobre 
o planejamento urbano, e que se alimentaram de si próprios, não existindo nenhuma vinculação com a realidade.

Em Passo Fundo e na sequência do debate promovido pelo Estatuto da Cidade, o município revisou o Plano Diretor de 1984, trabalho realizado com participação comunitária, exigência imposta pelo Estatuto da Cidade. O novo plano diretor, de 2006, buscou maior equilíbrio de usos e qualidade ambiental para a cidade. A intenção fica clara, quando analisamos as diretrizes básicas que nortearam o discurso e a lei no 170/06 do PDDI de 2006 e que abordam: I - redução das desigualdades sociais, através da ampliação da oferta de terra urbana, moradia, saneamento, infraestrutura, transporte, serviços públicos, trabalho, renda, cultura e lazer para os passofundenses; II - supremacia do interesse público sobre o interesse individual; III desenvolvimento municipal e regional sustentável; IV - participação e controle social sobre as políticas públicas; $\mathrm{V}$ - autonomia municipal e cooperação federativa. No artigo $4^{\circ}$, que aborda os princípios do desenvolvimento local, a função social da propriedade é considerada o núcleo fundamental do próprio direito de propriedade. Neste sentido busca a concretização de uma cidade mais sustentável através do equilíbrio entre o desenvolvimento econômico e a preservação ambiental, o planejamento participativo e a efetivação dos direitos sociais.

Mas como podemos avaliar se o discurso político e a lei norteadora do desenvolvimento municipal de uma cidade de porte médio, do interior do Rio Grande do Sul contribuirão para sua adequada expansão e desenvolvimento, materializando as diretrizes mais justas, sociais, ambientais e urbanísticas? Através da metodologia proposta de estudos comparativos da legislação e dos índices urbanísticos entre os planos diretores, pudemos aprofundar a narrativa em relação à preservação ambiental, ao planejamento participativo e a efetivação dos direitos sociais.

Numa análise inicial, constatamos que a questão social, a sustentabilidade e a participação cidadã são fatores contemplados no atual discurso político e na atual lei que rege o município. Neste estudo comparativo, verificou-se que o espaço urbano de Passo Fundo conformado pelo PDDU de 1984, e em especial sua zona central, contrastavam com as diretrizes de sustentabilidade preconizadas pelo Estatuto da Cidade, como a necessidade da participação comunitária na organização do território, que não houve, a ausência de uma legislação detalhada para a preservação ambiental, a falta de uma legislação para o controle da permeabilidade urbana, a priorização do transporte coletivo e a valorização do pedestre.

$\mathrm{Na}$ análise e nos estudos que nortearam este trabalho, também constatou-se que na revisão do plano diretor, novas regras restringiram discretamente a verticalização e a densidade na área central da cidade, incentivando, por outro lado, a densificação e verticalização nos bairros, otimizando a infraestrutura disponível em toda a área urbana. Desta forma, foram definidas novas formas de uso e ocupação do solo, menos restritivas ao uso do solo, incentivando a mistura de funções, dinamizando a vida urbana e evitando os longos deslocamentos que a setorização funcionalista preconizava. Ainda, uma clara definição das áreas permissíveis à expansão urbana e de outras com ocupação muito controlada, contribuem para uma legislação que transforma área urbana e rural do município.

Desta forma, o PPDI de 2006 tentou diminuir a tendência de concentração da verticalização urbana, permitindo maior adensamento nos bairros da cidade, com uso misto e diversificado, estabelecendo recuos edilícios obrigatórios com a obrigatoriedade de estacionamentos compatíveis ao porte das edificações. Dentre outras medidas tomadas na revisão do planejamento podemos então, pontuar:

4.1 Antigos distritos e centralidade urbana $\mathrm{x}$ macrozoneamento municipal - no PDDI de 2006, houve um avanço no planejamento municipal, sendo o território do município compreendido e tratado como um todo, único. O território municipal antes formado legalmente, por uma área urbana e outra rural, com seus distritos, e desvinculada dos processos urbanos, foi ordenado com funções definidas considerando-se a vocação e possiblidades locais, tendo-se especial cuidado na demarcação de zonas de preservação ambiental. O Plano de 2006 passa a tratar o desenvolvimento municipal legislando sobre todo o território, entendo as vocações do município como partes integrantes e relacionadas de um processo.

Neste sentido, a área rural, setorizada apenas por distritos administrativos, passou a ser tratada como parte formadora do território municipal, integrante e determinante da área urbana municipal, e assim definida: 01 Macrozona Urbana: porção territorial com predominância de funções urbanas, a cidade; 02 - Macrozona de Proteção dos Mananciais Hídricos: porção territorial que abriga parte da bacia hidrográfica dos rios Passo Fundo e Arroio Miranda, responsáveis pelo abastecimento de água; 03 - Macrozona de Produção Agropastoril: porção territorial com vocação para produção extensiva, com topografia ondulada, médias e grandes propriedades, lavouras extensivas de produção de grãos, reflorestamento comerciais e áreas de pecuária; 04 - Macrozona Mista: porção territorial com vocação agrícola de origem familiar, com topografia ondulada, alto índice de cobertura vegetal nativa e de reflorestamento, pequenas propriedades, atividades agroindustriais, olarias, suinocultura e avicultura; 05 - Macrozona de Produção Agrofamiliar: porção territorial de transição entre a Macrozona de Produção Agrofamiliar e a de Produção Agropastoril, com pequenas e médias propriedades, com agroindústria e agricultura familiar (Quadro 3). 


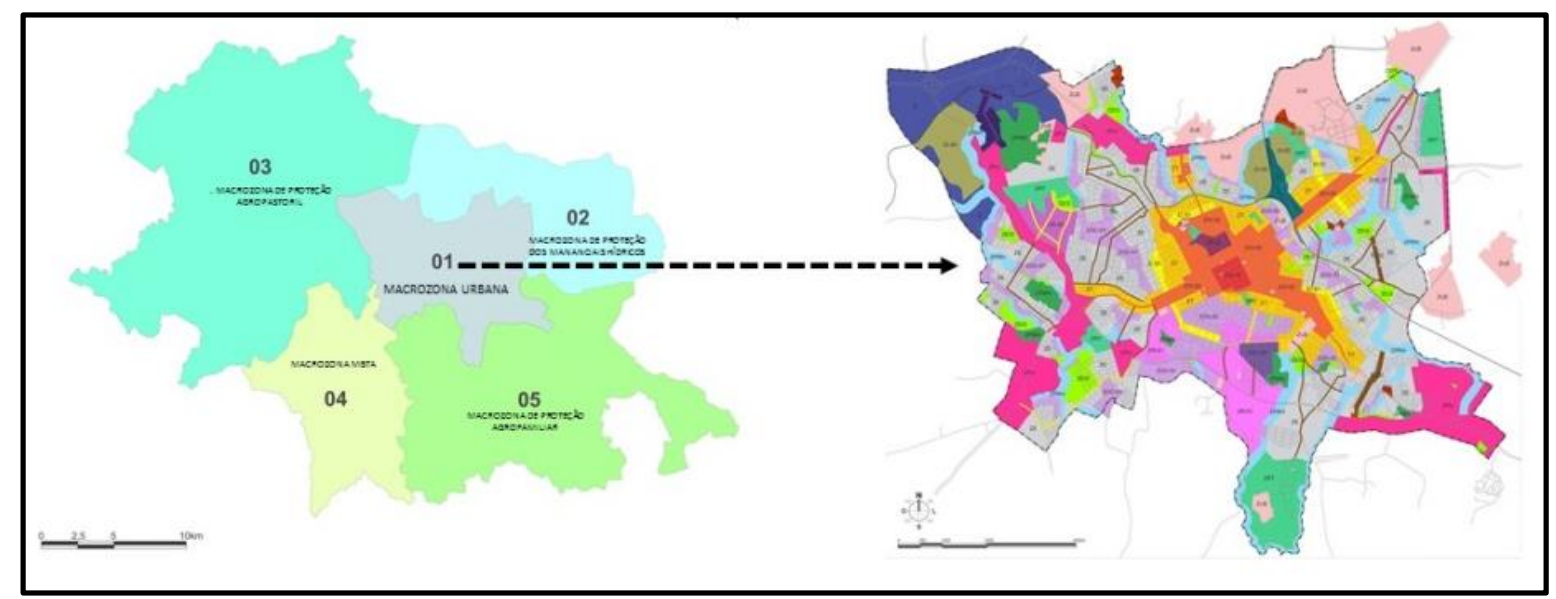

Quadro 3: PDDI - 2006 com macrozoneamento municipal e macrozona urbana. Fonte: PREFEITURA MUNICIPAL DE PASSO FUNDO (2014).

Em relação às áreas de preservação ambiental, foram definidas e detalhadas as áreas destinadas à proteção do ambiente natural e de sua recuperação, dividindo-se em: Zona de Proteção do dos Recursos Hídricos (ZPRH); Zona de Proteção da Mata Nativa (ZPMN); Zonas de Recuperação Ambiental (ZRA), Zonas de Ocupação Controlada Um (ZOC1); Zona de Ocupação Controlada Dois (ZOCD). A ZPRH passou a ter grande relevância, por abrigar as nascentes dos recursos hídricos, que abastecem a cidade. Em função disto, foi limitada a expansão urbana nesta direção, e ao mesmo tempo, induzido o crescimento da cidade na direção oposta. Ainda houve o cuidado do zoneamento e demarcação de áreas urbanas de preservação ambiental através de APPs, áreas de nascentes, de banhados, de bordas de córregos e rios urbanos.

4.2) Preservação ambiental e expansão urbana: as nascentes do Rio Passo Fundo, de onde é coletada a água para o abastecimento da população da cidade, encontram-se na região noroeste da malha urbana. Frente a esta questão, o Plano Diretor de desenvolvimento urbano de 2006, limita a ocupação do território naquela direção, quer proibindo o uso e a ocupação do solo ou limitando significativamente, a urbanização, os loteamentos e nestes, os índices construtivos.

Por outro lado, delimita claramente e promove a área de expansão urbana na direção oeste da cidade, nos setores oito e nove, por onde expande-se a cidade através de loteamentos planejados. Nesta área periférica, a pesquisa de campo identificou a implantação de significativas infraestruturas, como a abertura de vias, a aprovação de loteamentos populares que abrigam conjuntos habitacionais do programa "Minha casa, minha vida", a construção e ampliação de escolas de ensino infantil e fundamental e a demarcação de áreas de preservação ambiental.

Neste setor houve também uma parceria público-privada para a manutenção do Ginásio Teixeirinha, um bem público, que passou a abrigar a agremiação futebolística Esporte Gaúcho. A agremiação organizou e revitalizou uma edificação implantada em grande área, que se encontrava praticamente abandonada, resgatando para a comunidade, em especial a população dos setores oito e nove, em expansão, uma área de lazer e esportes.

Nesta revisão do Plano Diretor, constatou-se importantes avanços em relação a compreensão da questão municipal, quer seja na abrangência da legislação como também, quanto à demarcação das áreas de expansão urbana, pois diferente de outras áreas com loteamentos populares na cidade, tratados como apêndices, como o bairro Zácchia, nos setores oito e nove foram identificadas uma série de vias em implantação, que conectam os setores em expansão ao centro urbano da cidade, tratando-os, mesmo com expansão urbana, como partes integrantes da cidade formal. 


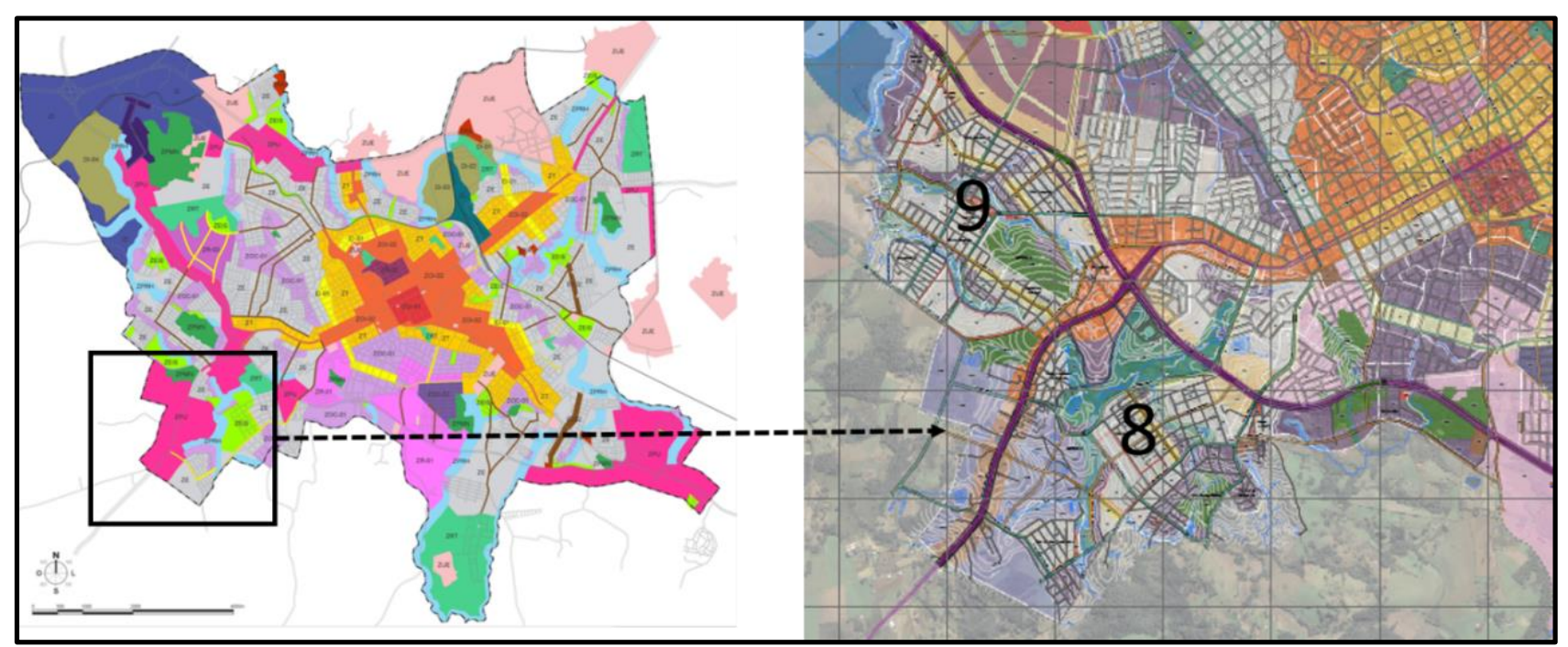

Quadro 4: Expansão urbana planejada na cidade de Passo Fundo: setores oito e nove

Fonte: PUL - Setores 8 e 9 / Passo Fundo - RS. BID, PMPF. 2013

A imagem contida no quadro 5 apresenta em detalhe, os setores oito e nove, áreas de expansão urbana da cidade de Passo Fundo. Esta região periférica é constituída, basicamente, como toda a periferia urbana das cidades do terceiro mundo, de hitações e conjuntos habitacionais de população de baixa renda. $O$ esforço do planejamento municipal destaca-se na proposta de integração urbana através da abertura de vias que conectam esta expansão à cidade formal. A pesquisa de campo registrou a execução de obras viárias, com pavimentação de pistas de rolamento e de passeios, a construção e qualificação de escolas, e uma parceria público-privada na construção de conjuntos de moradias dentro do Programa Minha Casa Minha Vida. O transporte publico conecta a população com equipamentos e trabalho, mas áreas de lazer em nivel local ainda são poucas. Nesta área, antigos caminhos e polos de assistência à comunidade carente emergem como subcentros locais, com escolas, posto médico, comércio diário e alguns serviços.

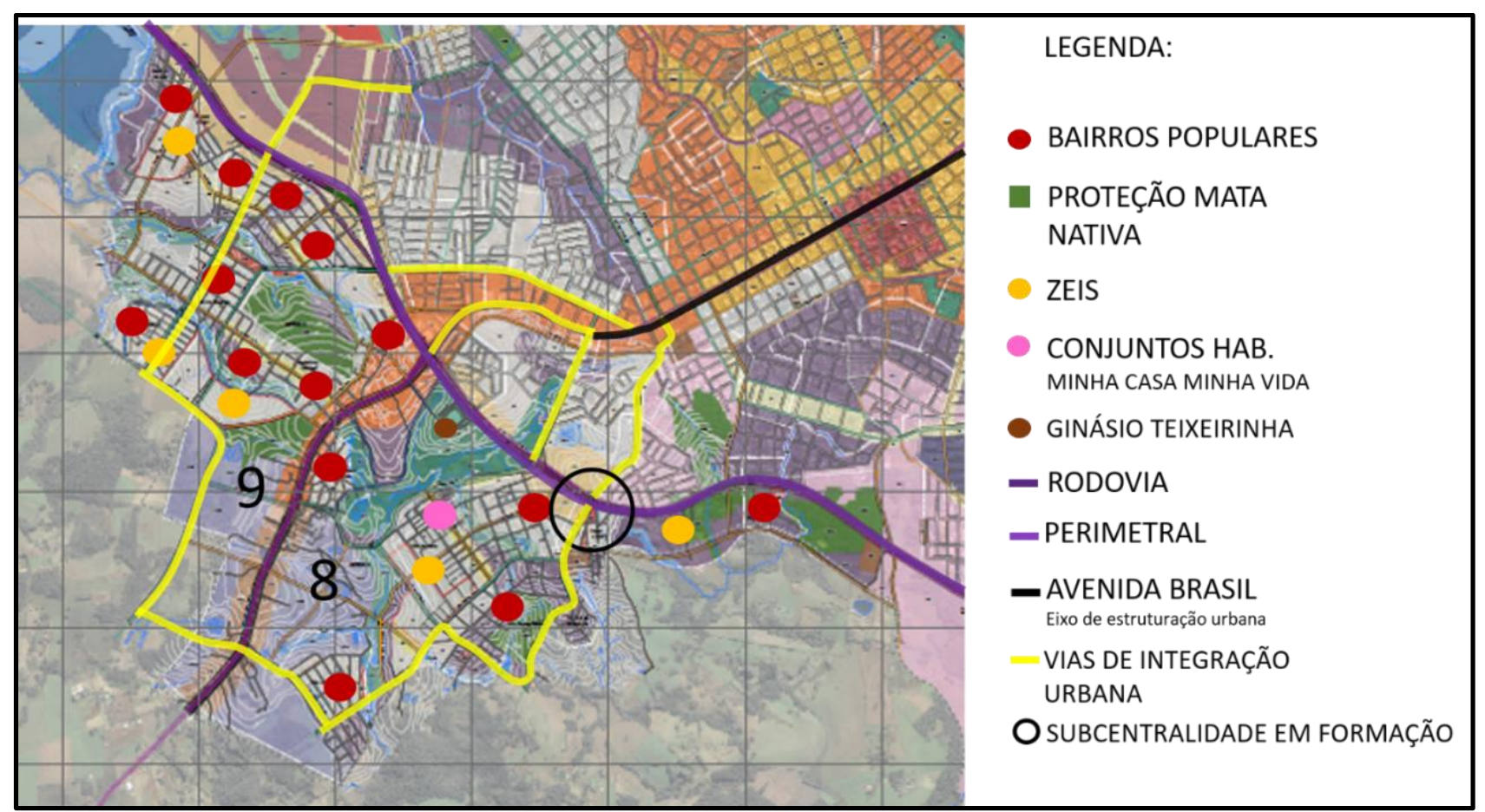

Quadro 5: Setores oito e nove - detalhamentos do território: infraestrutura, equipamentos e preservação ambiental.

Fonte: Fonte: PUL - Setores 8 e 9 / Passo Fundo - RS. BID, PMPF. 2013 
4.3) Zoneamento rígido $x$ diversificação do uso do solo - o PDDU de 1984 registrava uma Zona Comercial Central bem definida e quatro eixos comerciais, que acompanhavam os principais eixos viários da cidade em direção a quatro subcentros comerciais ainda emergentes, mas com poucas áreas de expansão de uso diversificado, no sentido transversal às vias. Circundando estas zonas e eixos comerciais, passava-se, imediatamente às zonas predominantemente residenciais. Foi um planejamento embasado em um zoneamento bastante rígido.

Conforme o Quadro 6, comparativamente, o PDDI de 2006 transformou a Zona Comercial Central em Zona de Uso Misto e ampliando a diversificação do uso do solo, subdividiu os eixos de expansão urbana em dois zoneamentos complementares: a Zona Mista e as Zonas de Transição. Com isto, pretendeu ampliar e densificar, controladamente, maior área urbana, aproximando periferias e centralidades por meio da diversificação e fortalecimento do uso do solo misto, evitando-se usos exclusivos. Na estrutura urbana proposta pela revisão do plano diretor, fica clara a intenção de reforçar os subcentros existentes, integrandoos aos eixos viários estruturadores. Estes eixos conduzem da zona central às zonas de ocupação mista e de transição (Quadro 6).

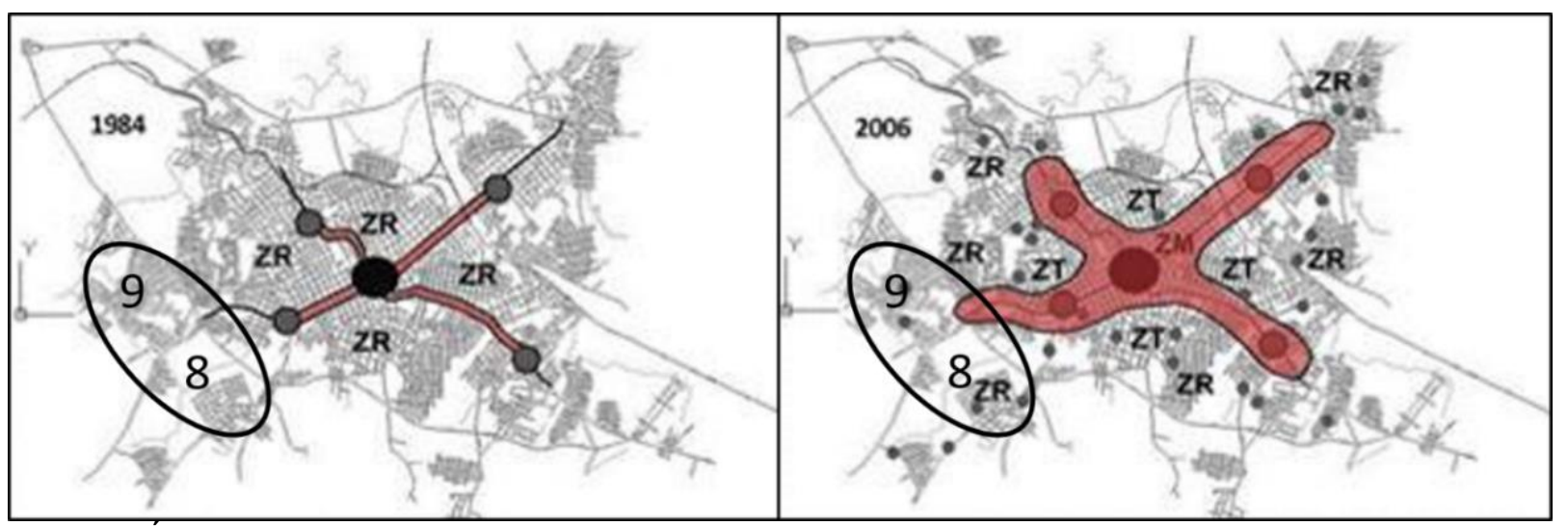

Quadro 6: Área urbana do município de Passo Fundo - Estudo comparativo de zoneamentos entre os planos de 1984 e 2006. Fonte: GELPI, A. et al. (2012).

4.4 Os eixos indutores como novos elementos de dinamização urbana - No PDDI de 2006 são propostos cerca de 50 "eixos indutores", inexistentes no PDDU de 1984, e que se constituem de parcelas urbanas que bordejam, atravessam ou dão seqüência às Zonas Mistas e de Transição. São projeções urbanas criadas com o objetivo de dinamizar áreas significativamente habitadas, mas que se encontram afastadas da Zona central e dos usos diversificados. Estes eixos indutores, implantados ao longo das vias onde circula o transporte coletivo, conectam vias locais e bairros periféricos a equipamentos urbanos e centralidades maiores. Com uma maior gama de usos e densidades permissíveis implantados em uma anterior zona prioritariamente habitacional de baixa densidade, os eixos têm como objetivo, dinamizar e expandir o uso do solo diversificado, integrando estes setores à malha e às demais funções urbanas, distribuindo e democratizando o acesso ao transporte e aos benefícios da cidade (Quadro 7). 


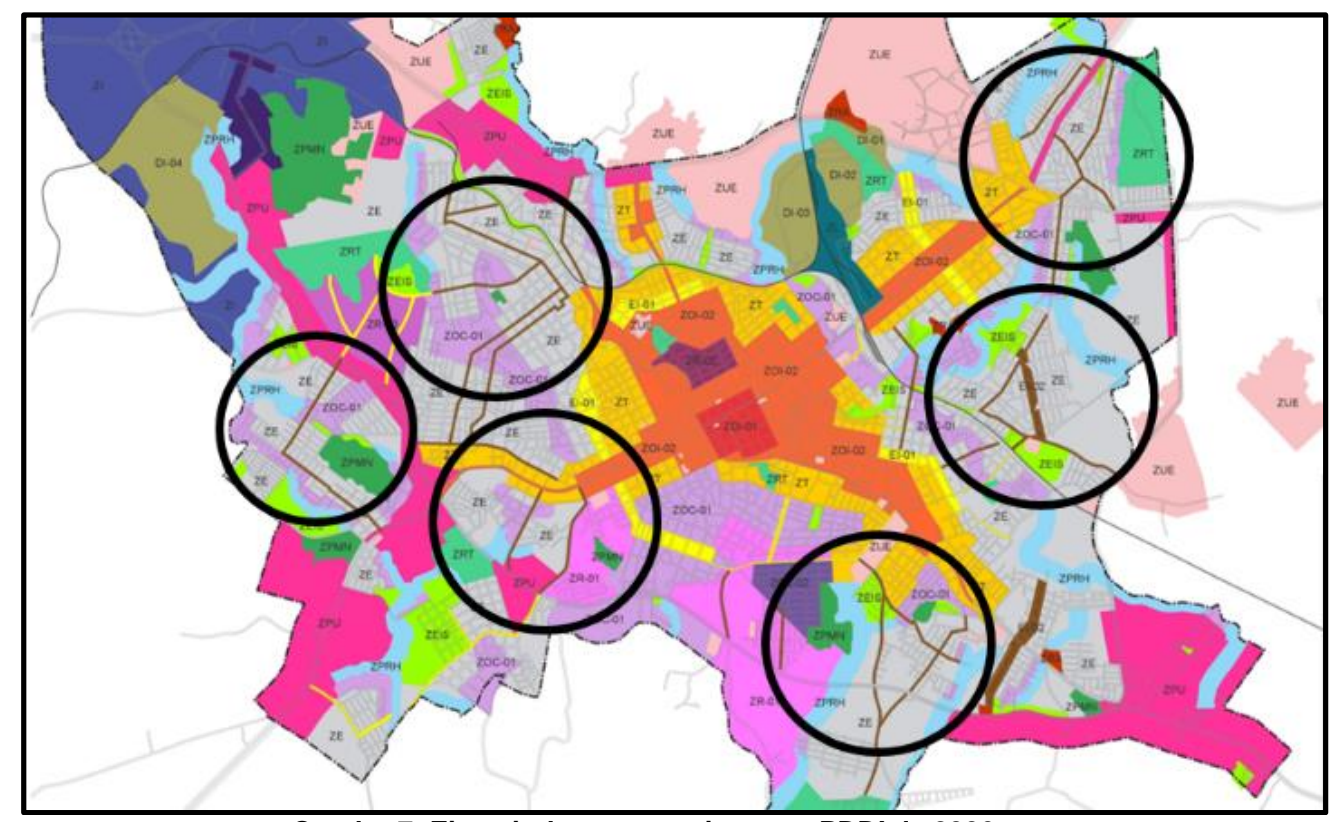

Quadro 7: Eixos indutores previstos no PDDI de 2006

Fonte: Adaptado de PREFEITURA MUNICIPAL DE PASSO FUNDO (2014).

4.5 Os índices construtivos - o PDDU de 1984 contribuiu para o adensamento e verticalização do centro da cidade. A permissão de taxas de ocupação elevadas, com pavimentos inferiores cobrindo todo o lote, até no mínimo, $12 \mathrm{~m}$ de altura, acarretou falta de espaçamentos mínimos entre os prédios - os recuos laterais entre as edificações, não permitindo aereação, ventilação e insolação adequada entre os edifícios. Mais que isto, a impermeabilização do solo através da construção maciça, já dificultava a drenagem urbana, alagando áreas da cidade após as chuvas. A falta de recuos frontais aproximaram os prédios em altura, criando estreitas vias de circulação, causando o sombreamento das edificações e dos passeios e ocasionando, também, 0 fenômeno de "túnel de vento", trazendo desconforto para os moradores e transeuntes.

Quando comparamos os dois Planos Diretores, especialmente em relação à zona central da cidade, constatamos que o PDDI, de 2006 propõe relativa restrição dos índices construtivos e das taxas de ocupação do solo. Propuseram-se recuos laterais e frontais obrigatórios, favorecendo a ambiência urbana através de aeração, ventilação e insolação. Também foi proposta uma taxa de permeabilidade, proibindo a impermeabilização total do terreno através da ocupação parcial do lote, permitindo a absorção das águas pluviais ainda dentro do lote urbano, evitando alagamento de vias, erosão do solo e comprometimento do patrimônio construído (Quadro 8).

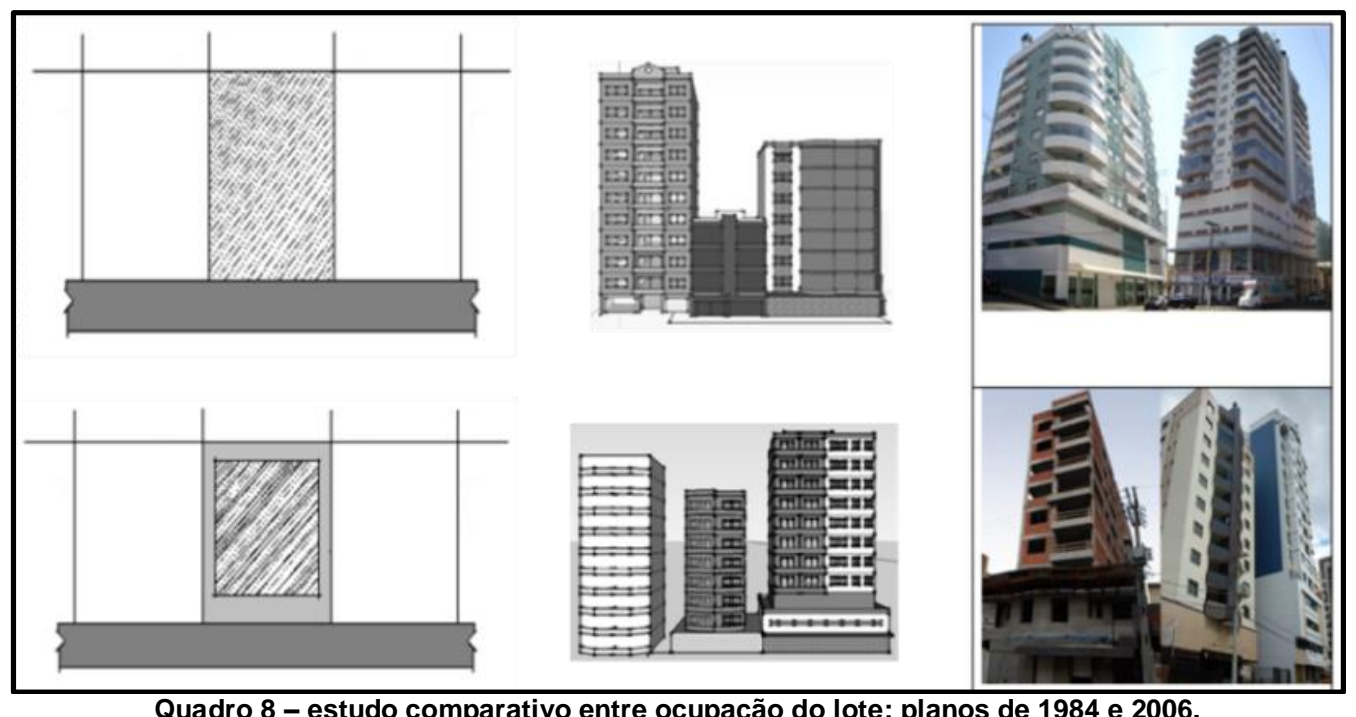

Quadro 8 - estudo comparativo entre ocupação do lote: planos de 1984 e 2006.

Fonte: GELPI, A. et al. (2012).

4.6 Áreas de lazer e de interesse social - no PDDU de 2006, e atendendo ao Estatuto da Cidade, houve a definição de Zonas Especiais de Interesse Social - as ZEIS, áreas para investimento público em habitação social. Também houve a definição e manutenção de áreas de preservação e de lazer intraurbanas, assim 
como em áreas não urbanizadas. Em relação às áreas de interesse social, a maioria delas está localizada em áreas periféricas, mas algumas se aproximam do principal centro urbano, onde já estão edificados alguns condomínios para população de baixa renda. Três áreas verdes destacam-se neste plano diretor: uma já existente e revitalizada, o Parque da Gare (1); outra de preservação, o Parque do Banhado do Vergueiro (2); e ainda mais uma área verde urbanizada, o Parque Linear (3). No Banhado do Vergueiro, implantou-se a Secretaria Municipal do Meio Ambiente, e no Parque Linear foram dispostos equipamentos e mobiliários urbanos. Todas estas áreas são abertas ao público, atendendo à demanda de lazer, educação, cultura e preservação (Quadro 9).

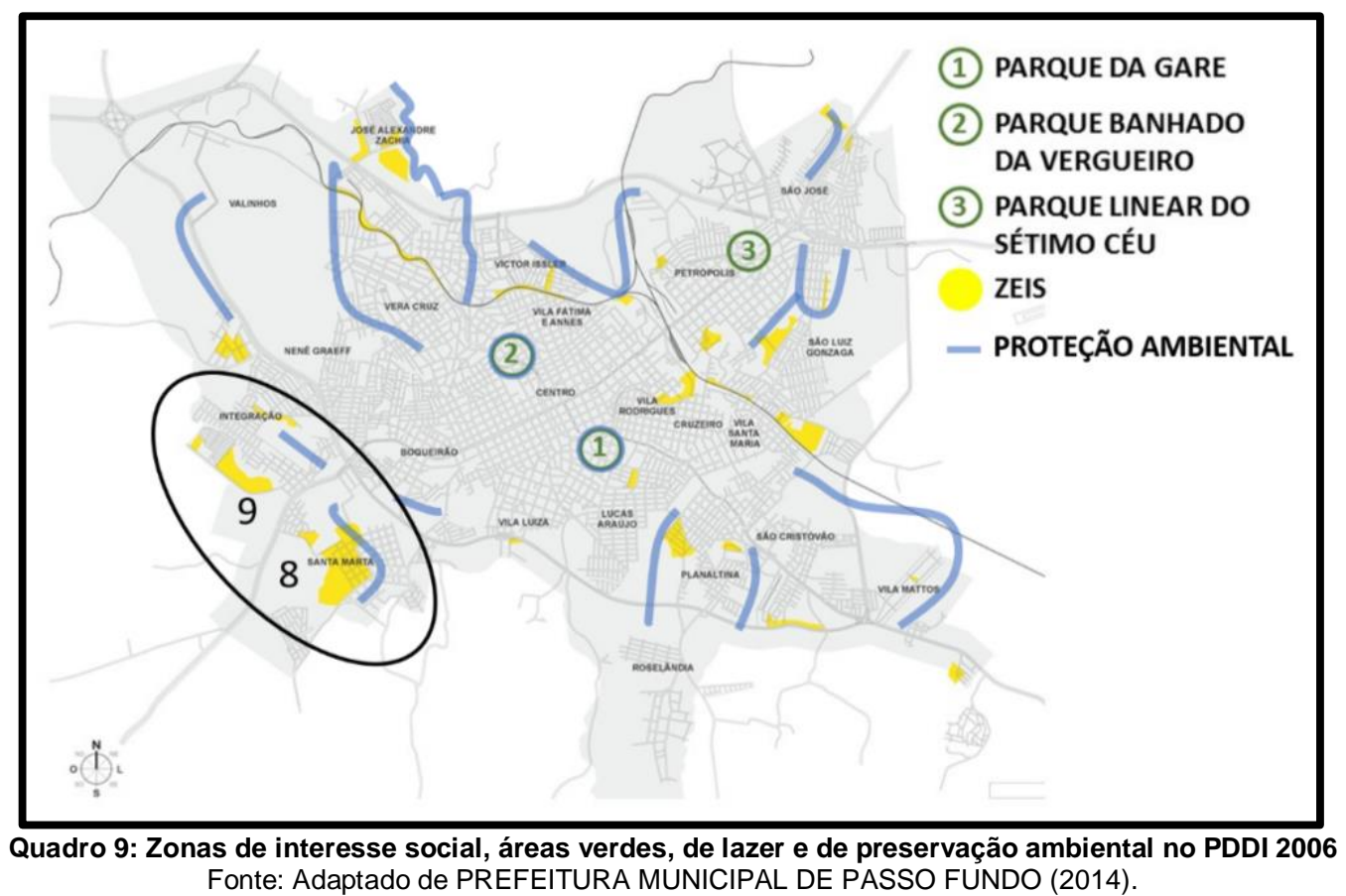

\section{CONCLUSÕES}

Frente à análise comparativa dos planos diretores e do levantamento de campo realizado para documentar a implementação do processo, podemos concluir que a revisão do plano diretor de Passo Fundo, implementada em 2006, buscou nas normativas gerais e sob orientação e diretrizes do Estatuto da Cidade, contemplar a democracia urbana e uma maior justiça social, através da legislação, diretrizes e indicadores. $O$ trabalho definiu e analisou parâmetros de sustentabilidade urbana, e num estudo comparativo, é possível afirmar que a revisão do documento traz propostas e legislação, que qualificam e democratizam, teoricamente, a vida urbana.

O zoneamento, a estruturação e organização funcional de toda a área municipal concebida e reconhecida através do PDDI de 2006, demonstram o avanço do corpo técnico municipal na compreensão do que trata o território de um município e a importante integração de suas funções e atividades sobre o território. A legislação também é bastante definitiva na área de preservação ambiental, entendendo a importância da preservação de remanescente florestais, do cuidado com orlas de rios e banhados urbanos.

A regulamentação avança ao vocacionar, mas não impedir o uso de atividades complementares e diferenciadas nas macrozonas não urbanas. $\mathrm{Na}$ área urbana, a diversificação do uso do solo em várias situações, dinamiza o espaço do cotidiano, trazendo nesta diversidade de uso vida e segurança aos cidadãos. Neste contexto, é importante registrar, em especial, a mescla de usos e a delimitação de várias áreas de interesse social.

A descentralização normatizada do uso do solo busca distribuir adequadamente os benefícios e equipamentos urbanos, conectando áreas periféricas a eixos indutores de desenvolvimento e às subcentralidades, aproximando bairros e áreas urbanas mais afastadas, de áreas mais bem servidas de facilidades e equipamentos urbanos, ao mesmo tempo em que induz através do uso do solo diversificado, novos empreendimentos em áreas onde havia predominância do uso habitacional.

Em relação aos índices construtivos, embora pequena, houve uma restrição geral à massa construída, especialmente na área central, já bastante saturada de edificações e que traziam sombreamento às áreas de recreação e convívio. Recuos frontais e laterais, restringindo índices construtivos foram propostos e implementados. Ainda foi normatizada e sancionada uma importante taxa de permeabilidade urbana, buscando, dentro dos lotes urbanos, uma maior absorção das águas pluviais e diminuição das enxurradas, 
trazendo benefícios e qualidade urbana para toda a população. Usos mistos permissíveis descentralizam, aproximam e diminuem distâncias, pois o uso do solo mais diversificado contribuiu para uma vida urbana mais democrática, mais justa, mais sustentável e acessível, procurando diminuir a necessidade de deslocamentos, promovendo e valorizando a vizinhança.

Ressaltamos, nesta conclusão o avanço no trato da periferia em expansão, os setores oito e nove, que abrigando população carente, recebe infraestrutura de conexão com o centro da cidade, com via em pavimentação e abrigando equipamentos urbanos que permitem melhor qualidade de vida.

Desta forma podemos afirmar que a qualificação urbana das cidades parte de uma legislação organizada de forma participativa, que valoriza a diversificação da estrutura urbana e a forma da cidade. Para tanto, também é necessário que esta legislação seja atendida, devendo sua implementação ser monitorada pela sociedade civil organizada, que faça cumprir as normativas propostas, através de seus conselhos municipais e outros mecanismos de participação cidadã.

\section{REFERÊNCIAS}

ANDRADE, L. M. Agenda verde $x$ agenda marrom - inexistência de princípios metodológicos para o desenho de assentamentos urbanos. 2005. Dissertação (Mestrado em Arquitetura e Urbanismo) - Faculdade de Arquitetura e Urbanismo, Universidade de Brasília, Brasília, 2005.

BRASIL. Estatuto da Cidade: lei 10257/2001 que estabelece diretrizes gerais da política urbana. Brasília, câmara dos deputados, 2001, primeira edição.

COMISSÃO DAS COMUNIDADESSES EUROPEIAS. Para uma estratégia temática sobre meio ambiente urbano. COM. Bruxelas, 2004.

DEAK, C. Uso do Solo - verbetes. http://www.fau.usp.br/docentes/deprojeto/c deak/CD/4verb/usodosolo/index.html. Acesso em 18/05/2017.

DÉAK, C e SCHIFFER, S. R. (org.) O processo de urbanização no Brasil. São Paulo, EDUSP,

DEL RIO, V. Introdução ao desenho urbano no processo de planejamento. São Paulo: Pini, 1990.

EDWARS, B. Guia básica de la sostenibilidad. Barcelona: Gustavo Gili, 2004.

EUROPEAN COMMUNITIES. Towards a local sustainability profile - European Common Indicators. Methodology Sheets. Luxembourg: Office for Official publications of the European Communities, 2001.

FEE - FUNDAÇÃO DE ECONOMIA E ESTATíSTICA. Municípios: Passo Fundo. Disponível em:<http:// www.fee.rs.gov.br >Acesso em maio 2008.

FREITAS, M. K; LOMBARDO, M. A. Índices urbanísticos e qualidade ambiental em áreas centrais de metrópoles: o caso de São Paulo. Mercator: Revista de Geografia da UFC, Fortaleza, v. 6, n. 12, 2007. Disponível em: < http://www.mercator.ufc.br/index.php/mercator/article/view/47/21 >. Acesso: 28 set. 2010.

GELPI, A.; KALIL, R. M. L.; SPIELMANN, T.; ROSALEN, A. D. Urban sustainability and spatial quality: urban law in medium-sized cities. International Journal of Energy and Environment (Print)., v.6, p.370 - 377, 2012.

GOSCH, L.R.M. Passo Fundo de Saturnino de Brito ao Mercosul: projetos e imagens urbanas. 2002. Dissertação (Mestrado em Desenho Urbano) - Faculdade de Arquitetura e Urbanismo, Universidade Federal do Rio de Janeiro, Rio de Janeiro, 2002.

ITDP-INSTITUTO DE POLÍTICAS DE TRANSPORTE E DESENVOLVIMENTO. Padrão de qualidade TOD v2.1. Rio de Janeiro, 2014.

JACOBS, J. Muerte y vida de las grandes ciudades. Madrid: Península, 1967.

PREFEITURA MUNICIPAL DE PASSO FUNDO. Plano Diretor de Desenvolvimento Urbano. Passo Fundo: 1984.

Plano Diretor de Desenvolvimento Integrado. Passo Fundo: 2006.

Plano Municipal de Saneamento Básico. Passo Fundo, 2014.

SCUSSEL, M. C. B. O lugar de morar em Porto Alegre: uma abordagem para avaliar aspectos de qualificação do espaço residencial, à luz de princípios de sustentabilidade. 2007. Tese de doutorado (Programa de PósGraduação em Engenharia Civil) Universidade Federal do Rio Grande do Sul, Porto Alegre, 2007. 
SOBARZO, Oscar. Passo Fundo: cidade média com funções comerciais, de serviços e de apoio ao agronegócio. In: SPOSITO, M. E. B.; ELIAS, D.; SOARES, B. R. (Org.). Agentes econômicos e reestruturação urbana e regional: Passo Fundo e Mossoró. São Paulo: Expressão Popular, 2010, p. 29-100.

TEDESCO, J. C.; KALIL, R. M. L.; GOSCH, L. R. M.; GELPI, A.; CORAZZA, J. Passo Fundo e a produção do território pós-anos 1950: migração e urbanização. In: BATISTELLA, A. (Org.) Passo Fundo, sua história. v.1. Passo Fundo: Méritos, 2007.

VILLAÇA, F. Espaço intraurbano no Brasil. São Paulo: Studio Nobel: FAPESP: Lincoln Institute, 1998.

VILLAÇA, F. Uma contribuição para a história do planejamento urbano no Brasil. In:

EDWARS, B. Guia básica de la sostenibilidad. Barcelona: Gustavo Gili, 2004. 